\title{
ARTICLE
}

\section{Analysis of Metabolism and Effective Half-life for Radiation Workers' Tritium Intake at Pressurized Heavy Water Reactors}

\author{
Hee Geun $\mathrm{KIM}^{1 *}$, Tae Young KONG ${ }^{1}$, Goung Jin $\mathrm{LEE}^{2}$, Woo Tae JEONG ${ }^{1}$, Seok Tae KIM ${ }^{1}$ \\ ${ }^{1}$ Korea Electric Power Research Institute, 103-16 Munji-dong, Yuseong-gu, Daejeon, 305-380, Korea \\ ${ }^{2}$ Chosun University, 375 Seosuk-dong, Dong-gu, Gwangju, 501-759, Korea
}

\begin{abstract}
Tritium is the one of the dominant contributors to the workers of Pressurized Heavy Water Reactors' (PHWRs) internal radiation exposure. This nuclide is likely to be released in work places as tritiated water vapor (HTO) from the primary system and can get relatively easily absorbed into the body of workers by inhalation. Inhaled tritium usually reaches the equilibrium of concentration after approximately 2 hours inside the body and is then excreted from the body with an effective half-life of 10 days. Because the tritium inside the body is transported within the body, the whole body can be exposed to radiation. Internal radiation exposure at PHWRs accounts for approximately $20-40 \%$ of the total radiation exposure, where most of the internal radiation exposure is attributed to tritium. Thus, tritium is an important nuclide that needs to be necessarily monitored for radiation management safety. In this study, metabolism for tritium was established by using its excretion rate results in urine samples of workers at PHWRs. An effective half-life, a key parameter that estimates the radiation exposure, was derived from these results. As a result, it was found that the effective half-life for workers at Korean Nuclear Power Plants (NPPs) was $7.43 \pm 2.22$ days, which is shorter than that of International Commission on Radiological Protection guides.
\end{abstract}

\section{KEYWORDS: pressurized heavy water reactor, tritium, urine sample, metabolism, effective half-life}

\section{Introduction}

Compared to Pressurized Water Reactors (PWRs), relatively large amounts of tritium are generated at Pressurized Heavy Water Reactors (PHWRs) because heavy water is used as a moderator and coolant at PHWRs. Although the quantity is small, a small amount of tritium can be released from a primary system to the air of a workplace. Thus, workers who entered the radiation-controlled area for work can get internal exposure to tritium. Internal exposure to tritium at PHWRs accounts for approximately 20-40\% of total radiation exposure. ${ }^{1)}$ Thus, tritium is an important nuclide that needs to be necessarily monitored for radiation management safety. ${ }^{2)}$

Tritium normally exists as a tritiated water vapor (HTO) in the workplace. This tritium can get into the body of workers by inhalation and absorption through skin. Inhaled tritium can reach the equilibrium of concentration after approximately 2 hours inside the body and is then excreted from the body with an effective half-life of 10 days. ${ }^{3,4)}$ Since inhaled tritium is transported within the body, the whole body can be exposed to radiation. ${ }^{5)}$ The effective half-life of tritium metabolism is one of the most important data for internal dose assessment of radiation workers that were exposed to tritium. An effective half-life of 10 days, which is recommended by the International Commission on Radiological Protection (ICRP), is currently used for internal dose assessment to tritium exposure at PHWRs. ${ }^{3,4,6,7)}$

In this study, the radiological characteristics and metabolism of tritium were investigated for internal dose assessment after tritium exposure. In particular, the application of tritium metabolism was examined by using the tritium monitoring results of urine samples from workers who were exposed to radiation during work at the PHWRs. In this process, metabolism equations were derived and an effective half-life, one of the key parameters for internal dose assessment, was newly calculated. Finally, on the basis of these results, the conservativeness of the dose calculation result was compared with the dose calculation result that uses an effective half-life recommended by the ICRP.

\section{Tritium Generation}

Tritium $\left({ }^{3} \mathrm{H}\right)$ has a physical half-life of 12.3 years and decays into helium $\left({ }^{3} \mathrm{He}\right)$ with an emitting beta ray. This emitting beta ray has $18.7 \mathrm{keV}$ of maximum energy and 5.7 $\mathrm{keV}$ average energy. ${ }^{5,8)}$ At PHWRs, tritium is generated by the $(n, r)$ neutron activation reaction between heavy hydrogen and neutron in the moderator and the Primary Heat Transport (PHT) system. ${ }^{9)}$ Most of the tritium is generated at a primary system while the tritium concentration continuously increases until it reaches equilibrium in a primary system. ${ }^{9)}$ Sometimes tritium is generated at PHWRs by a neutron activation reaction between boron or lithium and neutron. However, the amount of tritium generated by the neutron activation reactions between boron or lithium and neutron is trivial compared to the amount generated by the neutron activation reaction between heavy hydrogen and neutron. Table 1 demonstrates the primary reactions for tritium generation. ${ }^{10)}$ 
Table 1 Tritium generation by neutron activation of CANDU reactors

\begin{tabular}{ll}
\hline Pathway & Production rate $(\mathrm{Ci} / \mathrm{MW}(\mathrm{e}) / \mathrm{y})$ \\
\hline Lithium contribution & 1.0 \\
${ }^{6} \mathrm{Li}(\mathrm{n}, \mathrm{a})^{3} \mathrm{H}$ & \\
${ }^{7} \mathrm{Li}(\mathrm{n}, \mathrm{na})^{3} \mathrm{H}$ & 0.0001 \\
Boron contribution & \\
${ }^{10} \mathrm{~B}(\mathrm{n}, 2 \mathrm{a})^{3} \mathrm{H}$ & 2400 \\
${ }^{10} \mathrm{~B}(\mathrm{n}, \mathrm{a})^{7} \mathrm{Li}(\mathrm{n}, \mathrm{na})^{3} \mathrm{H}$ & \\
Deuterium $\left(99.8 \%\right.$ of $\left.\mathrm{D}_{2} \mathrm{O}\right)$ contribution & \\
$\quad$ Coolant system $(60 \mathrm{Ci} / \mathrm{MW}(\mathrm{e}) / \mathrm{a})$ & \\
Moderator system $(2340 \mathrm{Ci} / \mathrm{MW}(\mathrm{e}) / \mathrm{a})$ & \\
\hline
\end{tabular}

Table 2 Tritium retention half-lives in humans

\begin{tabular}{llllllll}
\hline & \multirow{2}{*}{$\begin{array}{l}\text { Reference } \\
\text { Investigators }\end{array}$} & $\begin{array}{l}\text { Number } \\
\text { date }\end{array}$ & & $\begin{array}{l}\text { During of } \\
\text { the study }\end{array}$ & & \multicolumn{3}{l}{ Biological Half-life (day) } \\
\cline { 6 - 7 } & & & & HTO & OBT-1 & OBT-2 \\
\hline Osborne & 1966 & 30 & - & 10.5 & - & - \\
Snyders et al. & 1968 & 1 & 255 & 8.7 & 34 & - \\
Lambert et al. & 1971 & 1 & - & 9.1 & 36 & - \\
Moghisst et al. & 1972 & 1 & - & 9.0 & 30 & 450 \\
Balonov & 1974 & 6 & 300 & 12.0 & $39-76$ & $100-120$ \\
Pinson and Langham & 1980 & 9 & - & 11.3 & - & - \\
Rudran & 1988 & 8 & 280 & 6.0 & $30-226$ & - \\
Trivedi et al. & 1995 & 8 & 300 & $5.0-12.8$ & $58-104$ & - \\
\hline
\end{tabular}

\section{Tritium Metabolism}

According to ICRP technical reports for reference man, when workers are exposed to the air contaminated by HTO, the tritium can enter the body in two ways: two thirds of the total intake amount for tritium is attributed to inhalation while the rest of intake is attributed to skin absorption. ${ }^{7)}$ All of the HTO that is inhaled by breathing is absorbed into the lung where the absorbed HTO is uniformly distributed throughout the body waters and soft tissues after approximately 2 hours. ${ }^{2-5,7,11)}$ In this equilibrium stage, it means that the concentration of tritium that is excreted from the body in urine equals to the amount of tritium located inside the body.

Most tritium exists as water inside the body. However, some tritium combines with organic molecules to form Organic Bound Tritium (OBT), even though the production rate is very low. This OBT has a relatively long effective half-life, but because of its small amount, the effects of tritium on internal exposure are not significant. For tritium, 10 days of effective half-life is currently used for internal dose assessment. ${ }^{3-7)}$ The effective half-lives for tritium that has been investigated until now are demonstrated in Table 2. $^{3-5,51)}$

In 1987, Johnson published a simplified tritium metabolism model that is composed of a body water and two OBT compartments. ${ }^{5)}$ This simplified metabolism model has been fundamental for use in internal dose assessment to tritium exposure..$^{10,15)}$ Particularly, in Johnson's model, tritium transportation inside the body is demonstrated by two OBT compartments. This model assumes that each OBT compartment has a different average residual time and that tritium is distributed uniformly throughout the soft tissue. ${ }^{5)}$ However, the physical structure of body water and the OBT compartment, as well as the combined characteristics for the other compounds were not considered. Fig. 1 shows the Johnson model for tritium metabolism. ${ }^{3-5)}$

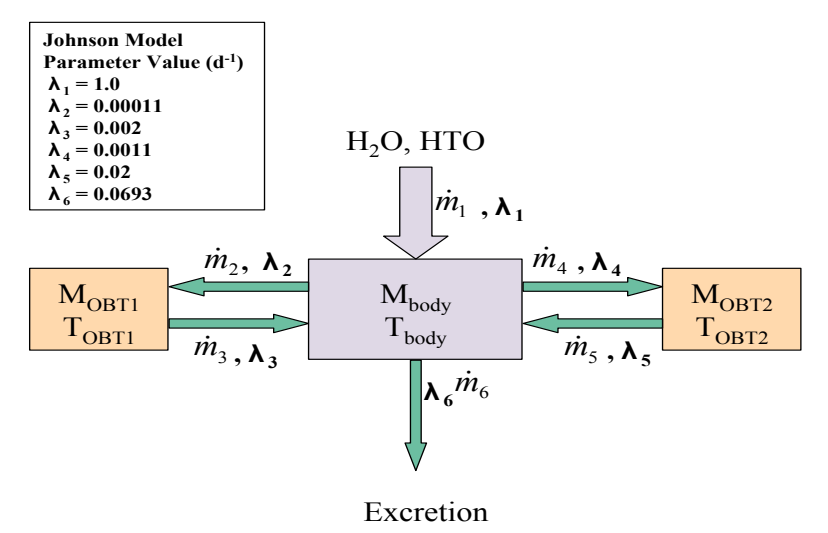

Fig. 1 Balance model for water and tritium intake

Retention equations for water and tritium for each compartment were derived from the transfer coefficients that were used in the HTO metabolism model. In a steady state, the retention equation for water that flows into the body is shown in Eq. (1)-(3). ${ }^{3)}$ 


$$
\begin{aligned}
\frac{\partial M_{O B T 1}}{\partial t} & =\dot{m}_{2}-\dot{m}_{3}=0 \\
\frac{\partial M_{O B T 2}}{\partial t} & =\dot{m}_{4}-\dot{m}_{5}=0 \\
\frac{\partial M_{B o d y}}{\partial t} & =+\dot{m}_{1}-\dot{m}_{6}+\left(\dot{m}_{3}-\dot{m}_{2}\right)+\left(\dot{m}_{5}-\dot{m}_{4}\right) \\
& =\dot{m}_{1}-\dot{m}_{6}=0
\end{aligned}
$$

Where, $M_{x}$ : mass of water at compartment $x(\mathrm{~kg})$,

$\dot{m_{1}}:$ transfer rate of water to compartment $x(\mathrm{~kg} / \mathrm{day})$. In a steady state, the equations can be expressed as $\dot{m_{1}}=\dot{m_{6}}, \dot{m_{2}}=\dot{m_{3}}, \dot{m_{4}}=\dot{m_{5}}$. This means that the amount of influx of water into each compartment equals the amount of efflux of water from each compartment, that is, the amount of influx into the body, $\dot{m}_{1}$, equals the amount of efflux from the body, $\dot{m}_{6}$. On the basis of this result, the retention equations for tritium are shown in Eq. (4)-(6). ${ }^{3)}$

$$
\begin{aligned}
& \frac{\partial T_{O B T 1}}{\partial t}=\dot{m}_{2} \frac{T_{B o d y}}{M_{B o d y}}-\dot{m}_{3} \frac{T_{O B T 1}}{M_{O B T 1}} \\
& \frac{\partial T_{O B T 2}}{\partial t}=\dot{m}_{4} \frac{T_{\text {Body }}}{M_{\text {Body }}}-\dot{m}_{5} \frac{T_{O B T 2}}{M_{O B T 2}} \\
& \frac{\partial T_{\text {Body }}}{\partial t}=-\dot{m}_{2} \frac{T_{\text {Body }}}{M_{\text {Body }}}+\dot{m}_{3} \frac{T_{O B T 1}}{M_{O B T 1}}-\dot{m}_{4} \frac{T_{\text {Body }}}{M_{\text {Body }}} \\
& +\dot{m}_{5} \frac{T_{O B T 2}}{M_{O B T 2}}-\dot{m}_{6} \frac{T_{B o d y}}{M_{B o d y}}
\end{aligned}
$$

Where, $T_{x}$ : tritium radioactivity at compartment $x(\mathrm{~kg})$.

Thus, if the above Eq. (4)-(6) are combined with those of the Johnson tritium metabolism, the transfer coefficients, $\lambda_{i}$ $(i=2, \cdots, 6)$ are shown in Eq. (7).

$$
\begin{aligned}
& \lambda_{2}=\frac{\dot{m_{2}}}{M_{B o d y}}, \quad \lambda_{3}=\frac{\dot{m_{3}}}{M_{O B T 1}}, \quad \lambda_{4}=\frac{\dot{m_{4}}}{M_{B o d y}}, \quad \lambda_{5}=\frac{\dot{m_{5}}}{M_{O B T 2}} \\
& \lambda_{6}=\frac{\dot{m_{6}}}{M_{B o d y}}
\end{aligned}
$$

Where, the transfer coefficients, $\lambda$, are expressed as the ratio of the amount of water that is metabolized over its mass in each compartment. Thus, the difference of the amount of tritium residual inside the body and the effective half-life are attributed to the amount of metabolism, $\dot{m}$, and water mass, $M$, in each compartment. In particular, for short-term exposure that has a low contribution of OBT, the internal dose is determined by transfer coefficients, $\lambda_{6}$, which is determined by the daily intake of water and water mass inside the body of each individual.

A simultaneous differential equation was used to evaluate the contribution of OBT that is combined organically inside the body to the tritium metabolism that is inside the body. As a result, the amount of tritium residual from body water and OBT2 passed each other at approximately 35 days after intake. This means that in less than 35 days after exposure to HTO, the effects of OBT to the amount of tritium concentrated inside the body is not significant. ${ }^{3)}$ Fig. 2 shows the results of the tritium's retention rate in the body. Furthermore, the amount of tritium concentrated in the body water compartment was calculated in cases where the OBT compartment was included in tritium metabolism equations and in cases where the OBT compartment was not included.

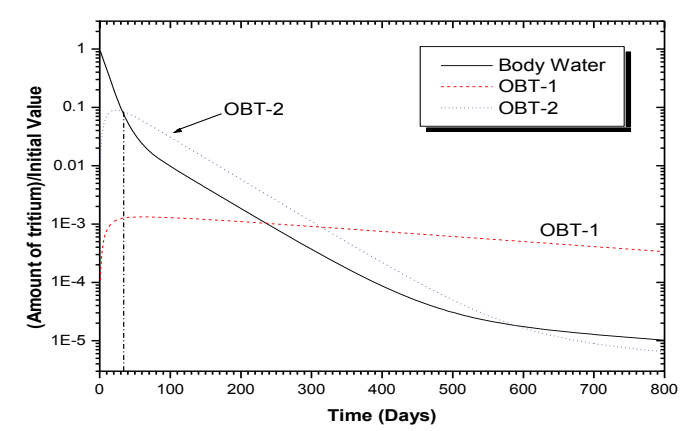

Fig. 2 Retention rate of tritium in body water and OBTs

\section{Effective Half-life of Tritium for Radiation Workers at Wolsong NPPs}

In order to evaluate the average effective half-life of tritium for NPP workers, the data of tritium concentration that were measured from the urine samples of radiation workers at Wolsong NPPs were used. ${ }^{3,16)}$ This data were made for the purpose of managing the radiation exposure of tritium for NPP workers during work. Thus, the continuity of the measurement time in urine was not good. In addition, because the effective half-life for tritium was calculated by using the initial and final tritium concentration in urine samples, there was a likelihood of error in the calculation process for the effective half-life. Thus, a removal constant for the tritium and initial tritium concentration inside the body were compensated by using the least square method. ${ }^{3,16)}$ As a result, it was found that the effective half-life for tritium is $7.43 \pm 2.22$ day ( $90 \%$ of confidence level) for radiation workers at Wolsong NPPs. Table 3 shows the effective half-lives based on the urine bioassay results of the Wolsong NPP's workers. ${ }^{3)}$ 
Table 4 Effective Half-lives based on the urine bioassay results of the Wolsong NPPs' workers

\begin{tabular}{ccccccc}
\hline No & $\begin{array}{c}\text { Weight } \\
(\mathrm{kg})\end{array}$ & $\begin{array}{c}\text { Duration of } \\
\text { observation (Days) }\end{array}$ & $\begin{array}{c}\text { Number of } \\
\text { measurement }\end{array}$ & $\begin{array}{c}\text { Initial concentration } \\
(\mathrm{MBq} / \ell)\end{array}$ & $\begin{array}{c}\text { Final concentration } \\
(\mathrm{MBq} / \ell)\end{array}$ & $\begin{array}{c}\text { Half-Life } \\
(\mathrm{Days})\end{array}$ \\
\hline 1 & 68 & 16 & 8 & 5.39 & 0.54 & 5.06 \\
2 & 60 & 36 & 13 & 9.24 & 0.46 & 8.14 \\
3 & 90 & 40 & 10 & 8.57 & 0.48 & 9.66 \\
4 & 63 & 18 & 7 & 3.31 & 0.59 & 7.11 \\
5 & 73 & 17 & 9 & 3.50 & 0.54 & 6.14 \\
6 & 60 & 21 & 5 & 3.31 & 0.43 & 7.99 \\
7 & 62 & 16 & 5 & 3.20 & 0.52 & 5.55 \\
8 & 68 & 23 & 6 & 2.34 & 0.11 & 8.42 \\
9 & 67 & 12 & 9 & 4.29 & 0.55 & 5.85 \\
10 & 60 & 26 & 11 & 6.90 & 0.26 & 6.98 \\
11 & 64 & 32 & 8 & 5.68 & 0.68 & 7.21 \\
12 & 72 & 13 & 6 & 2.19 & 0.57 & 7.80 \\
13 & 74 & 27 & 6 & 4.08 & 0.59 & 9.33 \\
14 & 60 & 19 & 6 & 2.86 & 0.46 & 8.48 \\
15 & 63 & 29 & 6.63 & Avg. & 1.650 & 7.43 \\
\hline
\end{tabular}

\section{Conclusion}

In this study, the application of tritium metabolism for internal dose assessment by using the monitoring data of tritium concentration in the urine samples of radiation workers at PHWRs was investigated for internal dose assessment to tritium exposure. In particular, a tritium metabolism equation was derived and the effective half-life, one of the key parameters for internal dose assessment, was newly calculated.

Measurements of tritium concentration were conducted on 15 Korean NPP workers who got internally exposed to tritium during radiation related work. On the basis of these monitoring data, the effective half-life was calculated for tritium exposure. As a result, it was found that the effective half-life for tritium is $7.43 \pm 2.22$ day with $90 \%$ of confidence level. This value is lower than the 10 days of effective half-life that is recommend by the ICRP. Thus, the current effective half-life for tritium used at Korean NPPs meets the ICRP guidelines. Particularly, because 10 days of effective half-life is used for internal dose assessment to tritium exposure, it was confirmed that the internal dose for tritium is calculated conservatively at Korean NPPs.

\section{Acknowledgment}

This research was carried out with the financial support of Korea Hydro \& Nuclear Power Corporation.

\section{References}

1) Korea Hydro \& Nuclear Power Co., Annual report for radiation safety management, (2007).

2) D. W. Whillans, K. S. Thind, Internal Dosimetry for Short-Range Emitters. Health Physics Society 1995 Summer School (Radiation Protection at Nuclear Reactors), Medical Physics Publishing Madison, Wisconsin, (1995).

3) H. G. Kim, T. Y. Kong, "Analysis of Metabolism and Effective Half-life for Tritium Intake of Radiation Workers at Pressurized Heavy Water Reactor," J. Radiation Protection, 34[2], 87-94 (2009).
4) H. G. Kim, T. Y. Kong, W. T. Jeong, S. T. Kim, “An Internal Tritium Concentration Analysis in Urine Samples as a Function of Submission Time after Airborne Tritium Intake at Korean Pressurized Heavy Water Reactor," J. Radiation Protection, 34[4], 184-189 (2009).

5) R. L. Hill, J. R. Johnson, "Metabolism and Dosimetry of Tritium," Health Physics, 65[6], 628-647 (1993).

6) International Commission on Radiation Protection, Individual Monitoring for Internal Exposure of Workers, Replacement of ICRP-54, ICRP Publication 78, Pergamon Press, (1997).

7) International Commission on Radiation Protection, Limits for intakes of radionuclides by workers, ICRP Publication 30, New York: Pergamon Press, (1982).

8) K. Y. Wong, T. A. Khan, F. Guglelmi, O. K. Kvetton, R. C. Macphee, Canadian tritium experience, Canadian Fusion Fuels Technology Project, Toronto, Ontario, Canada, (1984).

9) Korea Electric Power Corporation, Final Safety Analysis Report for Wolsong NPPs, Rev.31, (2000).

10) International Atomic Energy Agency, Methods for Assessing Occupational Radiation Doses Due to Intakes of Radionuclides, Safety Report Series No. 37, (2004).

11) M. I. Balonov, E. I. Dolgirev, I. A. Likhtarev, "Exchange kinetics and dosimetry of tritium oxide in man for different routes of administration," Health Physics, 27, 367-375 (1974).

12) W. R. Bush, AECL-4150; Assessing and controlling the hazard from tritiated water, Atomic Energy of Canada Limited, Chalk River, Canada, (1972).

13) D. M. Taylor, J. P. Moroni, J. O. Snihs, C. R. Richmond, "The Metabolism of H-3 and C-14 with Special Reference to Radiation Protection," Radiation Protection Dosimetry, 30, 87-93 (1990).

14) H. L. Butler, J. H. Leroy, "Observation of the Biological Half-life of Tritium," Health Physics, 11, 283-290 (1965).

15) Atomic Energy Control Board, Regulatory Document R-100; The Determination of Effective Doses from the Intake of Tritiated Water, (1987).

16) H. S. Lee, W. S. Kim, H. G. Kim, E. J. Kim, Y. H. Yang, “A study on the metabolism model for internal dose assessment by tritium and carbon-14 exposure," Proc. Korean Nuclear Society Fall Meeting, October (2002). 